\title{
LAS CÁRCELES INQUISITORIALES DEL TRIBUNAL DE CÓRDOBA*
}

por

\author{
Ana Cristina Cuadro García \\ Universidad de Córdoba
}

RESUMEN: En este artículo analizamos el estado de las celdas del tribunal de Córdoba: las secretas, las perpetuas, la cárcel de familiares y la de mujeres. El mal estado de las instalaciones y las lamentables condiciones de vida de ministros y presos era generalizado. Ello se debía, en gran medida, a la propia desidia de los cuadros inquisitoriales para paliar la ruina arquitectónica de la sede, a la apropiación indebida de los fondos destinados a su mantenimiento, a las reformas incoberentes y a la concepción que se tenía en la época de lo que debia ser una cárcel. Un panorama desalentador que generó en los presos no pocas enfermedades, reacciones como la fuga, el negarse a comer, el fingirse locos, el intento de suicidio y, finalmente, la muerte.

PALABRAS Clave: Inquisición. Córdoba. Cárceles. Alcázar.

ABSTRACT: This article studies the conditions in the cells of the Court of the Inquisition in Cordova: the secrets cells, those for life imprisonment, the family cells and those for women. The bad conditions of the premises and the appalling living conditions of ministers and prisoners were generalized. This was due, to a large extent, to the carelessness of the Inquisition in regard to alleviating the architectural collapse of the site, to the misappropriation of the funds aimed at its maintenance, to its inconsistent renovation and to the understanding of what a jail should be at that time. All this shows a discouraging panorama which produced widespread disease among the prisoners and reactions such as escaping, refusing to eat, pretending to be mad, trying to commit suicide and, finally, their death.

KEY WORDS: Inquisition. Córdoba. Jails. Fortress.

* Este trabajo ha sido realizado en gran medida en el marco de una beca de Iniciación a la Investigación concedida por el Consejo Superior de Investigaciones Científicas, que disfruté en el Instituto de Historia bajo la atenta supervisión del profesor Rafael Valladares. 


\section{INTRODUCCIÓN}

El Alcázar de los Reyes Cristianos fue sede de la Inquisición de Córdoba desde que los monarcas cedieron sus instalaciones al Santo Oficio cuando tuvo lugar la capitulación del reino nazarita. La fortaleza, que había estado dotada de un carácter eminentemente palaciego mientras los reyes vivieron en sus estancias, pasó a convertirse en un recinto en el que primaba, sobre todo, la salvaguarda del secreto inquisitorial. Y es que detrás de sus muros de piedra no sólo vivieron los ministros del tribunal sino también los reos, que desde que eran apresados debían convertirse en muertos para el exterior.

El análisis de las cárceles es imprescindible para comprender la magnitud de la incertidumbre que la Inquisición generaba. Incertidumbre en el pueblo, que nunca sabía si se las vería con ella, que vivía coartado y con el permanente respeto que generaba; incertidumbre también en las familias de los procesados, que eran desposeídas de todos sus bienes y estigmatizadas socialmente; $y$, más que en ningún otro, incertidumbre en los prisioneros, que no sabían por cuántos años podrían dilatarse sus procesos y que se veían en las celdas sin solución de continuidad, incomunicados y rodeados de palomina.

Las celdas aportan, además, una valiosa información colateral porque se hallaban en el corazón de la sede, junto a zonas de trabajo y vivienda de algunos de los principales miembros del tribunal. De esta forma permiten conocer mejor el desenvolvimiento cotidiano de esta Inquisición y las condiciones de vida de unos cuadros que acabaron compartiendo fortaleza, humedad, suciedad, y hasta maldiciones ${ }^{1}$, con los lamentos de sus prisioneros.

Pese a ello, las cárceles del tribunal de Córdoba adolecen de un análisis monográfico. Los grandes estudios de estos espacios carcelarios se han reducido tradicionalmente a alguna empolvada panorámica de tinte laudatorio ${ }^{2}$, y a obras diametralmente opuestas que o bien arremeten contra la situación de los prisioneros ${ }^{3}$, o bien defienden a ultranza los métodos inquisitoriales, humanos y

1 La visita de inspección de 1645 muestra que pesaba sobre el Alcázar una supuesta «maldición», después de la muerte de varios ministros en sus habitaciones, algo que tendría más relación con la calidad de vida de sus estancias que con el rumor popular porque, además, no era la primera vez que enfermaban sus habitantes y la gente no se atrevía a entrar en su interior. Véase AHN, Inquisición, Leg. 1855, exp. 3, ff. $28-59$ (respuestas del inquisidor don Gaspar de Arredondo a los cargos que le hicieron en la visita de inspección de 1645. Córdoba, 6 de diciembre de 1645) y también AHN, Inquisición, Leg. $1856^{1}$, doc. 1, f. 1 r. (sobre los enfermos en el Alcázar, 17 de septiembre de 1564).

2 De la PinTA Llorente, Miguel, Las cárceles inquisitoriales españolas, Madrid, 1949.

3 Destaca especialmente la famosa obra de Reginaldo GONZÁLEZ MONTANO, Algunas artes de la Santa Inquisición española descubiertas y bechas públicas. Aparte de los ejemplos que se ban distribuido en su correspondiente lugar dentro de la propia obra, hay además algunos otros en los que pueden contemplarse las mismas artes como en una especie de cuadros en su mismo ejercicio. Hemos añadido por vía de apéndice los elogios de algunos piadosos mártires de Cristo a quienes, a pesar de baber afrontado con constancia cristiana la pena de muerte por la confesión de su fe, los inquisidores los difamaron con sus artes de perfidia y defección, Heidelberg, 1567 (ed. de Francisco RuIZ DE PABLos, Madrid, 1997).

Hispania, LXV/2, núm. 220 (2005) 443-464 
cristianos ${ }^{4}$. La desideologización que vino de mano de las nuevas generaciones de historiadores de la Inquisición consiguió abordar el tema con intenciones ponderativas hacia unos y otros, presos y cuadros, con notables artículos al respecto ${ }^{5}$. Sin embargo, la Inquisición de Córdoba quedó al margen de esta renovación historiográfica y sus cárceles y sus presos han pasado de puntillas por la historia de la Inquisición española, olvidados entre los muros del Alcázar.

\section{EL CONTEXTO CARCELARIO}

La documentación muestra el estado de obra casi perpetuo de la sede del tribunal de Córdoba a través de los siglos, apuntando así a una endémica ruina arquitectónica que nunca remontaba el vuelo. Las lamentables condiciones de las celdas tienen su explicación atendiendo a distintas causas. Por un lado, la apropiación indebida de los fondos destinados al mantenimiento del edificio, algo que al final acababa afectando tanto a los presos como a los propios cuadros inquisitoriales. A ello se sumaban las reformas incoherentes, absurdas modificaciones que incluso pusieron en peligro la estructura del edificio y que en muchos casos tuvieron que ser replanteadas con los años, volviendo a la situación de partida. Pero, además, hay que tener en cuenta un factor básico: la concepción que se tenía en la época de lo que debía ser una cárcel, sin la que no es posible entender el funcionamiento interno del Alcázar.

Y es que hasta que a finales del siglo XVIII comenzaran a oírse voces por una dignificación de las instituciones carcelarias, el planteamiento punitivo no tenía prácticamente nada que ver con las prisiones. Se puede afirmar que hasta

4 La obra de DE LA PINTA es paradigmática en este sentido, op. cit.

5 Algunos frutos destacados de este esfuerzo son los artículos siguientes: TellechEA IDígoRAS, J. Ignacio: «Las cárceles inquisitoriales», Monográfico sobre las cárceles en España en Historia 16, 1978, pp. 55-67; GIL SANJUÁN, Joaquín: «Las cárceles inquisitoriales de Granada», Jábega, 28 (1979), pp. 19-28; VINCENT, Bernard, «Un espace d'exclusion: la prison inquisitoriale au XVI ${ }^{e}$ siècle», REDONDO, Augustin (coord.): Les problèmes de l'exclusion en Espagne (XVIe-XVIle siècles). Idéologie et discours, París, 1983, pp. 113-122; BLÁzQUEZ MIGUEL, Juan: «Aportación al estudio de las cárceles inquisitoriales murcianas. "La casa de recogidas» en el siglo XVIII", Anales de Historia Contemporánea, 4 (1985), pp. 36-69; BLÁzQuez MigueL, Juan: «La cárcel inquisitorial de la Penitencia, en Cuenca», Cuenca, 27 (1986), pp. 27-32; ALBERRO, SOLANGE, Inquisición y sociedad en México (1571-1700), México, 1988; SÁNCHEZ ORTEGA, Ma Helena: «La situación de los presos en las cárceles del Santo Oficio de Granada durante el siglo XVII", Espacio, Tiempo y Forma. Ha Moderna, 1988 (1), pp. 669-683; PORRAS ARBOlEDA, Pedro A.: «La represión inquisitorial: los hechos de Arjona y la cárcel de Jaén en la época de Felipe el Hermoso", Espacio, Tiempo y Forma. $H^{a}$ Medieval, t. V, 1992, pp. 261-276; HerzoG, Tamar: «El rescate de una fuente histórica: los libros de visita de cárcel (El caso de Quito, 1738-1750)», Anuario de Estudios Americanos, LII-2 (1995), pp. 251-261; DOMíNGUEZ ORTIZ, Antonio: "Aspectos cómicos de una institución trágica», en Los extranjeros en la vida española durante el siglo XVII y otros artículos, Sevilla, 1996, pp. 289-300; ALPERT, Michael: «Manuela de Almeida. Una mujer en la cárcel de la Inquisición», Historia 16, 2002, pp. 76-83.

Hispania, LXV/2, núm. 220 (2005) 443-464 
principios del siglo XIV la cárcel medieval europea no cumplió funciones coercitivas, sino de custodia de unos presos que podían ser atrapados casi por cualquiera. La captura de prisioneros de guerra en los contextos bélicos estaba generalizada, así como el secuestro para obtener una recompensa económica; mientras en el plano cotidiano, eran los propios interesados quienes solucionaban sus problemas, bien siguiendo la línea marcada por el peso de las costumbres, bien haciendo suyos duelos y venganzas que en ocasiones eran de rancia tradición familiar. No sería hasta el 1300, aproximadamente, cuando los monarcas europeos comenzaran a abogar por que la jurisdicción criminal fuera un monopolio exclusivo de la corona ${ }^{6}$, algo que en España se apunta con los Reyes Católicos. Sólo ellos, a través de las leyes y de los jueces, tendrían el derecho de decidir quién podía gozar de libertad y quién no, así como los diversos castigos en función del delito cometido. Sin embargo, el camino por recorrer era largo en una sociedad fuertemente marcada por la impronta del honor en las familias y en la que los monarcas tenían una capacidad limitada de control de las poblaciones?.

Este problema podría hallarse en la base de esa explosión de autoridad que era la aplicación de las penas: la legitimación del poder real, que haría que éste se multiplicara ante la falta de una vigilancia eficaz ${ }^{8}$. El auténtico castigo era un espectáculo disuasivo que se recibía públicamente y en el que pretendían establecer la ecuación a mayor miedo provocado, mayor eficacia ${ }^{9}$. Sin embargo, las penas corporales fueron dejando paso, desde mediados del siglo XVI, a otros castigos teóricamente más humanizados que surgían para paliar las necesidades económico-estratégicas de la corona. Muchos de los que movieron las galeras fueron presos, así como aquéllos que extrajeron azogue en Almadén para conseguir más plata, construyeron, mantuvieron y defendieron las plazas fortificadas en el norte de África o en la América española, presos, en fin, quienes a mediados del XVIII realizaron obras públicas como los proyectos urbanísticos de Carlos III para Madrid. La evolución de la penalidad desde los inicios del Estado Moderno debe mucho, pues, a la dificultad de encontrar hombres libres para realizar estas labores, aunque ello no les hiciera renunciar a esa pedagogía del miedo que exigía ejemplaridad y publicidad en las ejecuciones.

Pero, ¿qué hay de la privación de libertad como pena en sí misma? En palabras de Pedro Trinidad, durante la Edad Moderna «todavía no es pensable que un hombre pague a la sociedad por el delito que ha cometido con la sola privación de

6 Dunbabin, Jean: Captivity and Imprisonment in Medieval Europe, 1000-1300, New York, 2002 , p. 48.

7 Las diferentes normas legales de cada reino, los fueros privilegiados de Iglesia y nobleza, las costumbres a la hora de aplicar justicia y el amplio margen de autonomía en la solución de conflictos entre particulares permanecían en el cuerpo social, como barreras que dificultaban las acciones reformadoras de los monarcas. Véase TRINIDAD FERNÁNDEZ, Pedro: La defensa de la sociedad. Cárcel y delincuencia en España (siglos XVIII-XX), Madrid, 1991, p. 19.

8 Op. cit., p. 18.

9 TOMÁs Y VALIENTE, Francisco: La tortura en España, Barcelona, 1973, pp. 185-187.

Hispania, LXV/2, núm. 220 (2005) 443-464 
libertad $»^{10}$. Y es que durante la Edad Moderna, se empleaban como prisiones edificios altos y sólidos, que no habían sido objeto de delineación previa, tales como fortalezas, conventos y torres ${ }^{11}$. Cualquier habitación podía ser reutilizada para custodiar al reo, que no tendría más remedio que intentar sobrevivir en ese espacio durante el período indeterminado de su reclusión en esa suerte de cárcel preventiva que se muestra casi como un castigo anticipado.

Aunque no existieran prisiones como se las concibe actualmente, sí se encuentra una intención reformatoria y moralizadora en las galeras de mujeres ${ }^{12}$, las casas de recogidas ${ }^{13}$ y en los encierros de pobres, locos y vagabundos ${ }^{14}$-estos últimos no llegaron a aplicarse en España hasta el XVIII. Al tiempo que se les retiraba de una esfera social que perturbaban, se intentaba reconducir por los caminos de la decencia y decoro a las mujeres, por los caminos del trabajo ordenado a ellos, semillas de la futura prisión contemporánea ${ }^{15}$. Pero la apuesta de la Ilustración sería el hospicio, que fue pensado como un modelo ideal de taller en el que jóvenes huérfanos, pequeños delincuentes, mendigos y vagabundos podían aprender un oficio de provecho al tiempo que impulsaban económicamente al país ${ }^{16}$. Sin embargo, la acción represiva que se ejerció sobre los vagabundos a raíz del motín de Esquilache llevó a la creación de casas de corrección para encerrar a este sector madrileño. Del régimen semiabierto del hospicio se pasó a un recinto correctivo penal de gran disciplina ${ }^{17}$.

10 Trinidad Fernández, Pedro: La defensa..., op. cit., p. 26

11 En Vitoria la cárcel municipal se situó en el edificio del Ayuntamiento en 1507 (éste sería trasladado a otro lugar), y allí quedaría hasta su sustitución por la cárcel celular construida a mediados del XIX. Para el caso de Sevilla, el Santo Oficio se ubicó con sus presos en el Castillo de Triana, una antigua fortaleza árabe en la orilla derecha del Guadalquivir. Véase BAZÁN DíAz, Iñaki, La cárcel de Vitoria en la Baja Edad Media (1428-1530): estudio etnográfico, Vitoria, 1992; GONZÁLEZ DE CALDAS, Victoria, El poder y su imagen. La Inquisición Real, Sevilla, 2001.

12 Véase FIESTA LOZA, Alicia: «Las cárceles de mujeres», Monográfico sobre las cárceles en España en Historia 16, 1978, pp. 87-99.

13 La diferencia entre las galeras y las casas de recogidas es que en las primeras se sometía a una dura disciplina a sus ocupantes, que eran por lo general prostitutas y mujeres delincuentes de baja esfera. En las segundas, los métodos de corrección eran mucho más suaves y en ellas se encontraban mujeres que habían atentado contra la moral imperante, algunas de las cuales habían sido metidas en la casa de recogidas por sus propios familiares, para que se reformaran: casos de infidelidad conyugal, correspondencia ilícita... Un análisis de todas las casas de recogidas de Madrid a finales del XVII en SÁNCHEZ GómEZ, Rosa Isabel: Delincuencia y seguridad en el Madrid de Carlos II, Madrid, 1994, pp. 209-212.

14 La Iglesia se opuso a la creación de este tipo de centros a pesar de que, como en el resto de Europa, también en España hubo quienes se hicieron eco del argumento de separar al pobre bueno del ocioso vagabundo, del que se colegía la necesidad de recluirlos a todos para diferenciar unos de otros, ayudar a los primeros y someter al trabajo a los segundos.

is Oliver Olmo, Pedro: Cárcel y sociedad represora. La criminalización del desorden en Navarra (siglos XVI-XIX), Bilbao, 2001, p. 332.

16 TRINIDAD FERNÁNDEZ, Pedro: La defensa..., op. cit., pp. 34-44.

17 Op. cit., pp. 45-46. 
El estudio de las instituciones carcelarias muestra una serie de factores que el discurso de la Ilustración interrelacionó, con Bentham a la cabeza, para conseguir que la cárcel - no sólo las galeras de mujeres, las casas de recogidas ni los hospicios - adquiriera una significación social fuera de toda duda. La prisión se convertiría, así, en baluarte de un nuevo concepto de castigo, mucho más gradual y de tintes ejemplarizantes drásticamente contrarios a los del Antiguo Régimen ${ }^{18}$ —especialmente duro cuando trataba con alguien acusado de delito de lesa majestad ${ }^{19}$.

Entre los factores que alentaron el actual significado social del edificio carcelario destacó, además de la introducción de la idea de la piedad ${ }^{20}$, el cambio en el concepto de pena. De ser un castigo merecido, una venganza justa que había de llevarse a cabo contra un delincuente-pecador, pasó a perfilarse como una forma de encauzar a un individuo que había tenido un comportamiento desviado. De esta forma, el castigo sumaba la noción de utilidad que se ha mantenido hasta nuestros días, pasando de ser un arte de las sensaciones insoportables a una economía de los derechos suspendidos, en palabras de Michel Foucault ${ }^{21}$.

18 Sobre el nuevo concepto de castigo y sobre las lecturas interdisciplinarias que se han generado en este último siglo en relación con la cárcel como objeto de estudio de la nueva historia social, la antropología, el marxismo y la historia de las mentalidades, véase Pedro Oliver Olmo, Cárcel y sociedad..., op. cit., pp. 19-64.

19 El castigo que la justicia civil aplicaba a los que eran culpables de delito de lesa majestad era durísimo y suponía en sí mismo toda una muestra de poder y ejemplaridad para la población. Uno de los casos más conócidos es el de Damiens, torturado hasta la muerte en Francia en el siglo XVIII, y del que puede leerse su castigo en Michel FouCault, Vigilar y castigar, Madrid, 1978, pp. 11-13.

Para el caso particular de los castigos inquisitoriales, el Santo Oficio en teoría no mataba, por lo que no era el responsable último de estos padecimientos. En cualquier caso, el ejemplo de los asesinos del inquisidor Pedro de Arbués es significativo. Los autores, Juan de Esperandeo, Mateo Ram, Juan de la Badía, Vidal Durán y Tristanico, su escudero, padecieron castigos similares al de Damiens, aunque sin llegar a su extremo. Cortaron las dos manos de Esperandeo delante del lugar del crimen, lo arrastraron al mercado, en la horca le cortaron la cabeza y le hicieron cuartos, clavando sus manos en la puerta de la Diputación y, finalmente, tiraron el resto de sus trozos por el camino. Muerte similar le esperó a Vidal Durán. Otros cómplices fueron quemados vivos o en estatua. Algunos más se suicidaron, pero no por ello sus restos se libraron del escarnio. Éste es el caso de Francisco de Santa Cruz; después de que recogieran su cadáver, tras tirarse de una torre de las cárceles, fue quemado, y los huesos, vestidos con su camisa y metidos en una cajilla, fueron tirados al río Ebro. A otro suicida, Juan de la Badía, le arrastraron su cuerpo, lo hicieron cuartos y, como a otros compañeros, lo tiraron por los caminos. Véase la memoria de los autos celebrados en la Inquisición de Zaragoza desde 1484 hasta 1502 en LEA, Henry Charles, Historia de la Inquisición española, Madrid, 1983, pp. 852-879.

20 Para James CASEY, la idea de piedad se había introducido en el XVII en el sistema judicial por la influencia de la Iglesia, y tenía su expresión en las diversas cofradías dedicadas al socorro del criminal. La granadina de la Merced acompañaba a los condenados al cadalso y recogía los restos de los descuartizados para enterrarlos en su capilla, y la sevillana de la Santa Caridad rezaba arrodillada mientras se ejecutaba al preso para luego recoger su cadáver a las tres de la tarde, en recuerdo a la Crucifixión. Véase CASEY, James, España la Edad Moderna. Una bistoria social, Valencia, 2001, p. 289.

21 FOUCAUlT, Michel: Vigilar..., op. cit., p. 18.

Hispania, LXV/2, núm. 220 (2005) 443-464 
La cárcel-custodia perdió sentido a la par que se fue extendiendo el deseo de que existiera una sociedad disciplinada, en detrimento de la sociedad asustada que debía sortear las distintas tentaciones que se le iban ofreciendo. Las antiguas prisiones se convirtieron en lugares objeto de delineación en toda Europa y en Estados Unidos. Se procedió a incorporar conceptos como el de la calidad de vida de los presos, el aprovechamiento laboral de la estancia en la cárcel, la utilización del tiempo en ésta en proporción al delito cometido y, sobre todo, la ejemplaridad de la estancia en la prisión por suponer una triste privación de libertad sin que fuera necesaria la muerte pública como medida de impacto entre la población ${ }^{22}$.

La Ilustración gestó un discurso sobre las funciones del encierro y la importancia del edificio (tanto por dentro como por fuera), que colocó los cimientos de una redefinición del espacio carcelario, cuya figura más relevante es Bentham ${ }^{23}$ :

«Las cárceles son todavía unas sentinas de corrupción física y moral, que exhalan á veces un mefitismo que lleva las enfermedades y la muerte á unas largas distancias de ellas. El acinamiento de tantos infelices encerrados en un recinto estrecho y sin ventilación, su desaseo, su desnudez, su escaso y malsano alimento: todo esto reunido, solamente por una especie de prodigio, puede no producir una infección general y mortífera [...]. Si la atmósfera física que se respira en las prisiones es pestilencial para los cuerpos de los presos, no lo es menos para sus almas la atmósfera moral»24

Su planteamiento parte de que las cárceles eran lugares en los que sólo se llegaba a la corrupción física y moral del preso. De esta reflexión sobre la situación carcelaria se llegará a concebir un nuevo modelo de prisión, mucho más dinámico, en el que el edificio se dota de unos mecanismos capaces de reconvertir al individuo, que regresaría a la sociedad para ser el ejemplo cumbre de la eficacia del sistema. Éste no sólo habría logrado castigarle por sus delitos con el encierro, sino que, además, la prisión le rescataba de sus errores. Desde esta óptica, el cubículo del Antiguo Régimen pasó a ser un edificio trazado en fun-

22 «QQué debe ser una prisión? Es una mansión en que se priva a ciertos individuos de la libertad de que han abusado, con el fin de prevenir nuevos delitos, y contener á los otros con el terror del egemplo; y es además una casa de corrección en que se debe tratar de reformar las costumbres de las personas reclusas, para que cuando vuelvan á la libertad no sea esto una desgracia para la sociedad ni para ellas mismas». La obra de Bentham se conoció en España a través del trabajo de Esteban Dumont, Tratados de legislación civil y penal, obra extractada de los manuscritos del señor J. Bentham, Madrid, Impr. F. Villalpando, 1822 (el texto en pp. 34-35). (FraILE, Pedro: «El castigo y el poder. Espacio y lenguaje de la cárcel», Geo-Crítica, 57 (1985), monográfico, 61 pp., la cita en p. 17).

23 En el caso español fue Lardizábal quien se encargó de la problemática del castigo durante el siglo XVIII, en su obra Discurso sobre las penas, publicada por primera vez en 1782.

24 Cit. en Foucault, Michel, El ojo del poder, Madrid, 1979, p. 81.

Hispania, LXV/2, núm. 220 (2005) 443-464 
ción de unos objetivos, al que se aplicó el nuevo paradigma espacial y morfológico $^{25}$ que lo convertirían en la actual prisión moderna.

\section{LAS CÁRCELES INQUISITORIALES}

Las cárceles inquisitoriales fueron reclusiones preventivas, algo que venía dado no sólo por el contexto carcelario, como se ha visto, sino además por la necesidad de salvaguardar el secreto que formaba parte del procedimiento del tribunal. Se daba la paradoja, por tanto, de que había carcelería para los presuntos herejes que esperaban su proceso y para quienes cumplían su condena, si bien en otros calabozos, cuando ésta se hacía efectiva.

Sin embargo, a pesar de que la estancia en los calabozos inquisitoriales no era en absoluto cómoda, uno de los aspectos clásicos que ha generado más polémica es el de las condiciones de vida de los prisioneros, que ha hecho a unos y otros posicionarse de forma contradictoria al respecto. En este sentido, un punto clave es la frecuente comparación entre las celdas del Santo Oficio y las cárceles laicas, de las que suelen salir vencedoras las primeras.

En cualquier caso, las cárceles de la Edad Moderna compartían con las celdas inquisitoriales muchos de sus aspectos más negativos. La suciedad y las enfermedades eran compañeras cotidianas en estas dos prisiones preventivas que separaban a mujeres de hombres - pero que no aseguraban en absoluto que no se cometieran abusos contra ellas. La alimentación era escasa y mala en ambas, si bien el factor dinero mejoraba las raciones en cualquiera de las dos. El ruido de la cárcel municipal impedía dormir a sus reos por las noches, mientras el absoluto silencio de la inquisitorial atormentaba a estos otros prisioneros, compañeros de fatigas. Los calabozos del Santo Oficio, aunque han sido generalmente considerados más humanos que el resto, abrían la puerta a un mundo de severidad y piojos que distaba bastante de la teoría inquisitorial, que sí habría hecho de sus celdas unas estancias bastante más benignas. Así pues, las cárceles de la ciudad y las de la Inquisición suponían para los reclusos diferentes pesadillas, pero pesadillas todas, a fin de cuentas.

Aunque las miserables condiciones de vida de los reos estaban vinculadas al concepto de delito-pecado de la época; sobre todo, a la noción de castigo imperante, el panorama carcelario inquisitorial no fue monocolor. El Santo Oficio tenía distintos tipos de celdas, según la fase en que se encontrara el procèso del

25 El panóptico se adaptaría a las nuevas necesidades de las cárceles y ofrecería un grado aceptable de aseo y salubridad, habitaciones en las que se pudieran ejercer actividades laborales, separación de sexos, instrucción y una cómoda inspección de los presos. La forma arquitectónica es especialmente importante. Se tiende, por regla general, a dibujar una planta circular o trapezoidal con unas alas de celdas dispuestas hacia unos pasillos de acceso, que, a su vez, desembocan en el espacio central, permitiendo una accesibilidad rápida de los vigilantes a los reos. Véase FRAILE, Pedro, Un espacio para castigar. La cárcel y la ciencia penitenciaria en España (siglos XVIII-XIX), Barcelona, 1987, p. 146.

Hispania, LXV/2, núm. 220 (2005) 443-464 
prisionero. Y aún dentro de las de una misma clase, se apreciaban diferencias sustanciales. La posición socioeconómica permitía a algunos presos introducir elementos de bienestar que aliviaban el encierro continuado, incluso criados, la tan preciada compañía que tantos otros prisioneros solicitaban infructuosamente en las visitas a cárceles.

Pese a ello, el rasgo más característico del encierro inquisitorial no es esa perpetuación de las desigualdades sociales, sino la clara diferencia entre las condiciones de vida de las cárceles secretas y de las perpetuas. La dureza de las primeras, que a fin de cuentas no eran más que unas prisiones preventivas, contrasta enormemente con la libertad de las perpetuas, la carcelería que en realidad se aplicaba a los condenados.

\section{Las secretas}

Cuando alguien era detenido por la Inquisición, ingresaba directamente en las cárceles secretas, donde permanecía mientras se resolvía su caso. Estas celdas, pequeños cubículos para uno o dos prisioneros, se encontraban en el interior del Alcázar, en torno al gran patio central del ala occidental del edificio, dispuestas aquí y allá con algún patinillo como elemento articulador que les diera entrada y también distribuidas en las diferentes torres. Como su propio nombre indica, en ellas la incomunicación y la desinformación debían ser las protagonistas. Los procesos solían dilatarse largamente, para desdicha de los prisioneros, y durante ese tiempo ni podían recibir datos del exterior ni los de fuera conocer el estado de los reos. Sin embargo, los cuadros no siempre consiguieron asegurar la inviolabilidad de las cárceles, bien porque la triste realidad infraestructural de la fortaleza se aliaba con la picaresca de los reclusos, bien por la desidia y mala gestión del personal, que en ciertos casos permitió y hasta arregló contactos entre presos y gente del exterior.

A pesar de que en ocasiones los de dentro consiguieran obtener información del mundo que les era vedado, las secretas eran con diferencia los calabozos más dưros. Se puede afirmar con propiedad que el castigo de cárcel en las perpetuas resultaba un alivio respecto a la situación en que se hallaban mientras esperaban la resolución de sus asuntos. En este sentido, el deficiente estado higiénicosanitario de las secretas tiene mucho que decir. Se puede rastrear desde principios del siglo XVI a través de testimonios indirectos, de visitas de inspección y de la información que aportan las visitas de cárceles. Aunque éstas pueden parecer cuantitativas a priori, de su lectura atenta se extraen conclusiones generales sobre las condiciones de vida de los presos. Nos muestran un panorama de constantes abusos por parte del mal pagado despensero, de desidia inquisitorial a la hora de proporcionar a los prisioneros aquello que solicitaban en las visitas, un panorama en fin, de suciedad, enfermedades, depresión, locura y suicidios.

Se ha conservado el inventario de lo que ingresaron en las celdas la mayoría de los procesados que salieron en los autos de 1625 y 21 de diciembre de 1627 . 
Llama la atención que Francisco Correa llevara tan sólo una bolsa bordada con una imagen de la Virgen dentro y una estampa de San Pedro Mártir ${ }^{26}$. Ni una manta, ni un colchón, ni una almohada; algo que sólo puedo interpretar desde una intención de captatio benevolentiae bastante alejada de la realidad cotidiana del encerramiento.

La vida en las secretas de Córdoba era dura. Estaba limitada por el estrecho e incómodo espacio a ocupar y, sobre todo, por la inmundicia y excrementos de paloma que se disponían en torno a las celdas, como consecuencia de la apropiación indebida que algunos ministros habían hecho de muchas estancias, pasillos y patios. Como ejemplo, antes de entrar a la cárcel de la Fuente había un callejón sucio de palomina, un pasillo que en realidad no cumplía más funcionalidad que la de estar delante del calabozo, el suelo que en continuo ir y venir daba a la habitación en que vivía algún hombre, tal vez el mismo Francisco Correa. Si se echaba un vistazo alrededor de esta cárcel, en su espacio más cercano se vislumbraba a las auténticas colonizadoras del Alcázar (la cursiva es mía):

«Ítem más adelante luego se entra en una pieza pequeña donde está una pila grande donde viene a dar agua, y en ella crían palomas y no hay en ella otra cosa.

A la mano izquierda de esta desta (sic) está otra cámara angosta en la cual así mismo crían palomas.

De la dicha cámara angosta se sale a un patio pequeño y en él, a la mano izquierda, está una cárcel donde refirió el dicho Rosa que criaban Palomas.

Frontero está una puerta que va a dar a la cámara del tormento [...].

Volviendo al dicho patio de las cárceles a la mano derecha están dos piezas grandes y sobre la una de ellas está un palomar que refirió el dicho Rosa que había hecho el alcaide.

Más adelante en la misma acera están dos cuerpos de piezas arrimadas a la muralla descubiertas y mal paradas, las cuales parece que ban servido de palomar a donde de ordinario parece baber babido gran suma de palomas, y de presente las bay.

Más adelante otras tres piezas grandes, las dos descubiertas y la otra techada, que parece haberse caído o derrocado, $y$ al presente se crían palomas, que se refirió el dicho Rosa no servían de otra cosa» 27 .

26 AHN, Inquisición, Leg. 1854, exp. 1, s.f. Entrada 126.

27 AHN, Inquisición, Leg. $4723^{1}$, ff. 1v-2r. (GRACIA BoIX, Rafael: «La sede inquisitorial de Córdoba —el alcázar de los Reyes Cristianos-en el último tercio del siglo XVI», Temas cordobeses, Córdoba, 2001, pp. 109-127; la cita en pp. 115-116). Una situación similar parecía vivirse en la sede del tribunal de Toledo. El informe que se elevó en 1630 mostraba unas instalaciones dotadas de 23 celdas, pero de las que 7 carecían de la seguridad suficiente por culpa de las palomas. Y es que seis daban al patio de un cuartillo convertido en gallinero y en la cárcel baja que estaba en dicho patio había colocadas también dos vigas para albergar gallinas, de forma que «las personas que entran se an de comer a las dichas gallinas». Por otro lado, la llamada celda de la contaduría también había sido convertida en palomar. AHN, Inquisición, Leg. $3104^{1}$ (BLÁzQUEZ MIGUEL, Juan, La Inquisición en Castilla-La Mancha, Madrid, 1986, p. 19). 
La pila a la que daba el agua era usada para criar palomas, así que los presos que no contaban en su celda con una pequeña servidumbre tenían que ir a la entrada de la cárcel llamada Botica, donde existía una de la que podían tomar agua para su aseo personal. Además, el agua que bebían no debía ser demasiado buena, habida cuenta de la petición del licenciado Villena, preso en la cárcel de los Naranjos, quien el 18 de junio de 1569 solicitaba «dos libras de açucar para veber agua» ${ }^{28}$.

Algunos calabozos estaban techados (cárcel del Chorrillo, de Campillo y de la Torrecilla), pero también había celdas descubiertas, como las dos que se encontraban en la cárcel nueva. En cualquier caso, presentaban como elemento común la suciedad. Y es que la palomina se había hecho dueña de la mayor parte de los patios y habitaciones, hasta el punto de que en caso de llegar una nueva presa había que limpiar de excrementos alguna de las celdas para instalarla ${ }^{29}$.

Durante los casi siete meses que el inquisidor don Alonso Tamarón cumplió con la obligación de visitar las celdas un sábado cada dos semanas, la petición más frecuente de los presos fue la de ropa y calzado, seguida muy de cerca por los que solicitaban algo con que mejorar las condiciones del jergón en el que pasaban el día. No les venía mal que se les proveyera de mantas, paja, lienzo para los colchones, crin, hilo para remendar e incluso alguno de ellos pidió el jergón mismo. Tampoco faltaba quien aprovechaba aún más lo poquito que tenía, solicitando unas tijeras para reutilizar una sábana y hacerse con ella unos calzones.

Los abusos del despensero y la falta de cuidado que ponía en la alimentación de los prisioneros tienen también su reflejo en el caso de Florián Rodríguez. Recluido en la torre del Homenaje, se quejó el 30 de julio de 1569 porque el despensero no sólo no había sustituido la vaca por paloma (previo aviso del preso de que le hacía daño comer vaca), sino que además al día siguiente de pedírselo se había quedado sin su ración de carne. Sin embargo, a pesar de que los abusos se producían, los inquisidores eran conscientes de que cambiar de despensero suponía un peligro harto considerable, teniendo en cuenta que entraría uno nuevo pero saldría una persona que había estado en contacto con todos los presos y que estaba al tanto de la evolución de sus procesos. A esto se sumaba que el mísero sueldo que percibía un despensero dificultaba encontrar un sustituto. De esta forma empleaban sus esfuerzos en reñir al alcaide que tenían ${ }^{30}$.

28 AHN, Inquisición, Leg. $1856^{1}$, s.f.

29 «Frontero en la otra acera más adelante está otra cárcel que llaman la Partida, la cual así mismo tiene otro patio como el susodicho, y en ella crían palomas, y de presente se está limpiando la palomina que ha dentro para meter en ella una mujer que se ha traído presa.» AHN, Inquisición, Leg. $4723^{1}$, f. 3r. (GrACIA BoIX, Rafael: «La sede...», op. cit., p. 117).

30 Por ello, los inquisidores avisaron a Antón Martínez, que detentaba el puesto en 1569, de que se haría información sobre las quejas de los encarcelados y que se le castigaría por lo que resultara culpable, amén de que desde ese momento en adelante se le ordenaba que pesara delante de ellos sus raciones, en definitiva, que procurara que cesaran las quejas de los prisioneros. AHN, Inquisición, Leg. $1856^{1}$, s.f. 
La falta de ropa para vestirse, de calzado y de un lecho digno no empañaba otras necesidades vitales que también eran solicitadas en algunas de las visitas de cárceles, tales como una mínima higiene personal y la limpieza de sus trapos. En este contexto no es extraño que se cuenten tantos enfermos entre los prisioneros. Suciedad, mala alimentación, humedad, escasez de luz y reclusión por tiempo indeterminado se conjugaban para minar su salud.

A los problemas físicos que los presos padecían con mayor dolor en su encerramiento (en muchas ocasiones, provocados por ello mismo, como se ha tenido ocasión de ver), se unían además las constantes quejas por la lentitud de los proce$\operatorname{sos}^{31}$, la incertidumbre sobre el tiempo de duración del cautiverio, la desconfianza hacia el compañero de celda debido a los «moscas»32, la escasez de luz ${ }^{33}$, los grillos que algunos llevaban puestos ${ }^{34}$, la humedad ${ }^{35}$, las pulgas ${ }^{36}$, las burlas de los muchachos - que no dudaban en tirar piedras e higos a los reos desde las escombreras e higueras cercanas a la torre del Homenaje, para desconsuelo de los presos cordobeses $^{37}$ - , la absoluta soledad en que algunos se encontraban en sus celdas ${ }^{38}$...

31 «Henoc, que le despachen su causa.» Cinco de marzo, cárcel de la Bóveda. Ibídem.

32 Un mosca es un falso prisionero que a modo de espía es introducido en la celda con el reo a fin de entresacarle la verdad. Nicolau EYMERIC ya hablaba en su Manual de Inquisidores de la posibilidad de usar este recurso y Reginaldo GONZÁLEZ MONTANO, con su eminente finalidad práctica, advertía de ello a sus lectores en caso de que fueran atrapados por la Inquisición. Según éste los moscas podían encontrarse entre los mismos prisioneros, congraciados con los Inquisidores para obtener algún tipo de privilegio durante su cautiverio, fuera de los calabozos, entre los confesores, e incluso en el extranjero (GonZÁlez MONTANO, Reginaldo: Artes..., op. cit.).

33 Hernán Rodríguez y Diego de Mesa pedían el dos de abril algo de sol, que se les dejara salir un poco al corral para airearse. A Andrés Baena lo que le preocupaba era la falta de luz por la noche, con un candil le bastaba. AHN, Inquisición, Leg. $1856^{1}$, s.f. Aunque las disposiciones inquisitoriales prohibían que se dejara luz a los prisioneros (por el peligro que implicaba de favorecer su huída), Andrés de Baena finalmente consiguió que le dieran un candil para la noche. Ibídem, p. 11r.

34 Miguel Pérez pedía que le quitaran los grillos (2 de abril, cárcel de las mozas), al igual que Joan Merlo (16 de julio, ocupó el lugar del anterior) y Joan de Vergara (16 de julio, cárcel de la chimenea). Ibídem.

35 «En la botica, Bartholome de Quesada, que la carçel esta humida y duerme en el suelo.» Dos de abril de 1569. Ibídem.

36 Un ejemplo de ello es el caso del marinero inglés John Hill, capturado en 1574 por la Inquisición canaria, y que se quejó de tener que dormir en el suelo, lleno de pulgas, careciendo de pan y agua, habiéndole dejado casi desnudo. Véase DE GRAY BIRCH, W.: Catalogue, I, p. 235 (KAMEN, Henry: La Inquisición española. Una revisión bistórica, Barcelona, 1999, p. 183).

37 El 30 de julio, desde la torre del Homenaje, «Fray Alonso dixo [...] que le tiran piedras por una cumbrera que tiene la carçel. [...] Florián Rodríguez [...] la higuera que.está en el omenaje, que se quite por que no tiren los mochachos [...].» AHN, Inquisición, Leg. 1856 ${ }^{1}$, s.f.

38 El 22 de enero de 1569, Luisa Martín estaba sola en la cárcel del Portillo. En la visita inquisitorial no pidió otra cosa que no fuera "compañia», al igual que el licenciado Villena y fray Alonso de Vergara, en sus celdas respectivas, a pesar de que éstos compartían habitación con un compañero. El licenciado abandonaría su petición, fray Alonso rara era la semana que no cejaba en su empeño. Después de que Luisa tuviera una compañera femenina durante unos siete días (le llevaron a Isabel Rodríguez, que sólo había estado una semana en la cárcel del Horno), volvió a verse sola en 
configurando un entorno propicio para que la depresión se cebara sobre los prisioneros ${ }^{39}$.

A todo lo dicho se sumaba lo penoso que de por sí era el mero hecho de haber sido encarcelado por la Inquisición - con lo que implicaba de estigmatización social- para provocar en algunos reclusos reacciones que iban desde la fuga ${ }^{40}$ hasta el suicidio ${ }^{41}$, pasando por estadios tales como la negativa a ingerir alimentos $^{42}$ o el fingirse $\operatorname{locos}^{43}$. Todo ello si no morían aplastados por las pie-

su calabozo y de nuevo pidió compañía, pero en esta ocasión también solicitaba «mas bino». Ninguna de sus dos peticiones le fueron concedidas, hasta que el 30 de julio se la encuentra con dos compañeras más, Ana Mexía y Francisca García. Ibídem.

39 Para que esto no sucediera con Andrés de Baena "ques melancolico», se dispuso el dos de julio que se le pusiera un compañero en la misma celda. Ibídem. Aunque el hecho de estar acompañado en la celda no siempre era motivo de alegrías, como comprobaban los inquisidores de Sevilla en 1562, cuando procuraban del Consejo de la Suprema un breve para relajar al recluso Hernán Ruiz Cabeza de Vaca, que había herido mortalmente a Diego Guillén, un presbítero compañero suyo de cárcel. AHN, Inquisición, Leg. 2943. (DE LA PINTA LlORENTE, Miguel: Las cárceles..., op. cit., p. 156).

40 No faltaban los casos de quienes, tras asistir al encarcelamiento de conocidos y parientes, se fugaban antes de que los recluyeran. Rodrigo Pérez, mozo soltero vecino de Córdoba, dejó dicho antes de su desaparición que iba a viajar hasta las Indias Orientales de Portugal «sin saberse a donde ni a que parte dellas». Fue quemado en efigie el 8 de marzo de 1598. (Gracia BoIX, Rafael: Autos de fe y causas de la Inquisición de Córdoba, Córdoba, 1983, p. 358).

41 Un ejemplo cordobés lo encontramos en el caso de Alonso López de Acuña, que «[...] Se dio Garrote de noche en su cama dandose tres bueltas a la Garganta con vna Tomiza de Palma con que estaua liada la escoba, y vna Reata de Rehilado de sus Calçones. Las quales bueltas auia ido retorciendo con vna mano de Mortero de madera, hasta ahogarse». Ibídem, p. 403.

42 Ésta fue una de las estrategias utilizadas por el mercader astigitano Francisco Sánchez, de cuarenta y cuatro años, para matarse. Ibídem, p. 343. Dentro de las causas despachadas en el auto de 25 de marzo de 1597.

43 En el siglo XIV, Nicolau EYMERIC aconsejaba a los inquisidores sobre las artimañas de los presos y de entre los diez puntos que resaltaba el noveno se refería a que en ocasiones los prisioneros «pretenden ser tontos o locos, y contestan con risas o incoherencias." En el caso de que realmente estuvieran locos, los inquisidores deberían intentar curarlos y no castigarlos (EYMERIC, Nicolau, Manual..., op. cit.). Un siglo más tarde, con la Inquisición moderna ya instaurada, las instrucciones de Fernando DE VALDÉs (1561) recogían que si los presos perdían el juicio se les tenía que proveer de defensor y que no se debía dejar a sus parientes que alegaran en su defensa; serían los miembros del tribunal los que harían las diligencias oportunas para saber la verdad de lo sucedido, si el preso estaba ya loco o había enloquecido en la cárcel. Véase BN, Mss. 935, f. 35 r.

En el caso del ermitaño Martín del Monte pende la duda más que razonable sobre si realmente había perdido el juicio o sólo fingía estar loco, como hacían otros. Después de algunas audiencias con él, el tribunal de Córdoba resolvió enviar a la Suprema informe en el que exponían que Martín se encontraba "pareciendo manifiestamente ser loco" y fue llevado a la casa de los locos de Sevilla. Su causa fue una de las resueltas por el tribunal cordobés entre el 10 de marzo de 1598 y el 30 de abril de 1599. (Gracia BoIx, Rafael, Autos de fe..., op. cit., p. 360). Beatriz Hernández, portuguesa acusada de judaizar también «Estando presa en las cárceles les pareció estar loca y falta de juicio y como tal se puso en la casa de los locos desta ciudad». Su causa aún estaba pendiente en el Consejo, se estaba tramitando entre febrero de 1581 y febrero del año siguiente. Ibídem, p. 175. Sin embargo, 
dras de sus calabozos, como le sucedió a Leonor Fernández en 1654, que fue sepultada por su celda cuando ésta se le cayó encima la madrugada del 30 de enero ${ }^{44}$. Los avisos del tribunal a la Suprema sobre el derrumbamiento del techo de la capilla de San Acacio y la caída de otros muros de celdas ${ }^{45}$ no pudieron evitar el trágico desenlace, con Leonor muerta y su compañera «maltratada», ejemplo máximo del mal estado de las cárceles secretas cordobesas ${ }^{46}$.

Para cuando se leía la sentencia a los presos habían pasado años, por lo general, en estas condiciones. Llegaba entonces el momento de cumplir la pena impuesta, que podía ser tan variada como la muerte en la hoguera, los azotes o

en AHN, Inquisición, Leg. 2423, s.f., encontramos el más curioso caso de fingimiento de locura de este tribunal. Se trata del que protagonizó a mediados del XVII Juan de Cuebas. Él mismo se jactaba de engañar al Santo Oficio en los alcázares y sería su propia esposa quien delatara sus artimañas para fingir locuras, entre las que se contaban «madrugar y hartarse de vino».

En otro orden de cosas, el recurso al fingimiento de la locura era universal para escapar de cualquier prisión. A este respecto, se encuentra el caso de un condenado a muerte por la justicia sevillana que, tras conocer su sentencia, quedó inmóvil durante nueve meses en la misma posición en la que se encontraba, ofreciendo un espectáculo cuanto menos lastimoso: «[...] y en todo este tiempo no habló ni pestañeó; y se proveía de su persona en los calzones, sin moverse de un lugar ni pedir de comer, lo cual le daban a tiempos; y comía y bebía si se lo daban. Y hirviendo de piojos y chinches que hacían nido en él, como si fuera pared, y sudando de calor por el aposento en que estaba, jamás hizo sentimiento de cosa alguna; demás de que tan mala gente como hay en la cárcel le hacían notables daños e injurias dándole a comer verijas de lana con suciedad, y las comía y sufría palos y libramientos y otras cosas... Y así por el mal olor y porque los presos y administradores y enfermeros de la enfermería daban peticiones que inficionaba la cárcel y se sacase della, y sus deudos pedían que fuese llevado a la casa de los locos [...]" Fue finalmente enviado a ella, donde permaneció diez meses más en la misma actitud hasta que un día escapó, haciendo que Cristóbal de Chavez llegara a afirmar que "Este ha sido el loco más cuerdo del mundo...» (GACTO FERNÁNDEZ, Enrique: «La vida en las cárceles españolas de la época de los Austrias», Monográfico sobre las cárceles en España en Historia 16, 1978, pp. 11-54; la cita en p. 35).

44 «M.P.S. Damos quenta a V.A como domingo 30 del proximo pasado a la una de la noche se undio una carçel secreta donde estauan Leonor Fernandez Martos, judaiçante, y Juana de Llamas, por superstiçiosa, por el uracan que ubo aquella noche, y al ruydo y uoçes acudieron el Alcayde y su ayudante y sacaron con arto trauajo a dicha Juana maltratada y a la dicha Leonor muerta y suffoca$\mathrm{da}$, de que estamos con todo sentimiento de no hauerse logrado la preuençion que hiçimos de mudar los presos que estauan en carçeles al pareçer algo peligrosas a otras, y la carçel que se undio era la mas segura pero como el tiempo es tan peligroso por las muchas aguas suçede lo mesmo en muchas casas desta çiudad y para asegurar el peligro de adelante hemos mandado las vean los maestros para el reparo que se pueda offreçer hasta que se mejore el tiempo. Dios guarde a V.A. Inquisicion de Cordoua y febrero a primero de 1684.» AHN, Inquisición, Leg. 2436, s.f.

45 Ibídem, carta de 26 de enero de 1684.

46 No sólo las paredes, sino también los techos, adolecían de arreglos las más de las veces. Ejemplos significativos que muestran el mal estado de las celdas y, a un tiempo, las duras condiciones de vida de los reos, son las cartas que el tribunal mandó al Consejo de la Suprema entre 1674 y 1675 informando sobre este asunto, y en las que describía vívidamente la techumbre de cañas que cubría sus cabezas o cómo «[...] el tejado y zaquezami de la carçel alcoba se jundio todo haçiendose pedaços todos los materiales por estar podridos y gastados [...]». Véase AHN, Inquisición, Leg. 2433, s.f.

Hispania, LXV'/2, núm. 220 (2005) 443-464 
el destierro. Si eran condenados a prisión, sumaban a sus espaldas otra carcelería, aunque ésta ya tenía unas connotaciones muy diferentes.

\section{La cárcel perpetua}

Las llamadas cárceles perpetuas, o también de penitencia, eran aquéllas a las que iban los condenados a prisión. Los inquisidores podían señalar un número exacto de meses o años de cárcel, condenar al sujeto en cuestión a cárcel perpetua o bien a cárcel perpetua irremisible. La diferencia se cuenta en años. Aquellos condenados a cárcel perpetua en realidad no solían estar encerrados más de tres años, pero siempre vinculados a la voluntad posterior del primer inquisidor, que pasado ese trienio era quien finalmente podía dar la libertad o mantener la carcelería unos cuantos años más. La cárcel perpetua irremisible no era un encierro eterno, como puede pensarse a priori. En realidad, acumulaban nueve o diez años en un particular régimen de prisión abierta para que su caso pasara a ser tenido en cuenta, como en el ya expuesto, por el primer inquisidor, quien solía liberarlos.

El régimen de vida de este encerramiento era, paradójicamente, mucho mejor que el de los detenidos en las cárceles secretas - algunos de los cuales demostrarían posteriormente su inocencia. Debido a los graves problemas de espacio que tenían en Córdoba, estos presos no se encontraban ya en el interior del Alcázar, sino que se solían alquilar casas anejas a la fortaleza, donde cumplían su pena. El celo de seguridad que regía la vida en las perpetuas no era tan fuerte como el que se tenía en teoría en las secretas. Éste, de hecho, no era necesario, pues a pesar de que no hubiera unas especiales medidas de control, en algunos tribunales no se han encontrado casos de evasiones y suicidios ${ }^{47}$. Sin embargo, en el tribunal de Córdoba el problema del espacio se mantenía inalterable, se tratara de la cárcel que se tratara.

A la altura de 1588 , la cárcel perpetua estaba ubicada en una casa que la Inquisición tenía arrendada por treinta y cuatro ducados anuales. Su estado dejaba bastante que desear; pequeña y mal arreglada, solamente contaba con una estrecha habitación para los hombres en la que apenas si entraban tres presos, y, más adentro, otras tres pequeñas para mujeres, donde tampoco cabían, en realidad, más de cuatro o cinco reas. De esta forma, no extraña que el prisionero y las cinco presas que se encontraban en ella el 2 de abril de 1569, al ser tan pocos, no se quejaran en la visita de inspección que realizó el inquisidor Alonso Tamarón, sino que, muy al contrario, todos dijeran «[...] que cumplian bien sus penitencias, y que estaban vien recogidos y procurados del Alcaide» ${ }^{48}$.

47 Tal es el caso del tribunal de Córdoba y del sevillano, como afirmó Domínguez OrTiz, Antonio: «Aspectos...», op. cit., p. 294.

48 AHN, Inquisición, Leg. $1856^{1}$, exp. 7, s.f. 
Sin embargo, la capacidad de la cárcel perpetua era limitada y no siempre se halló en relación con las necesidades reales del tribunal. Ello no fue óbice para que, en cualquier caso, éste hiciera uso de las dependencias, metiendo en ellas muchos más presos de los que podían estar de forma digna. La situación no hizo más que empeorar en una época de intensas persecuciones contra los moriscos, por lo que los aprietos y estrecheces obligaron a los inquisidores a plantearse dos posibles soluciones. O bien comprar la casa de un vecino tintorero y arreglarla para cárcel perpetua -incluso se plantearon tirarla abajo y levantarla de nuevo-; o bien, por otro lado, aprovechar unos lienzos de muralla que había en una haza de los alcázares para edificar sobre ellos una cárcel nueva, cercana a los inquisidores y, además, propia, con lo que el gasto de la construcción se lo ahorrarían no pagando más arrendamiento ${ }^{49}$.

A pesar del hacinamiento y de la precariedad arquitectónica ${ }^{50}$, los presos gozaban de un régimen de libertad que hacía que el encarcelamiento no fuera tan riguroso como el de las cárceles secretas, algo bien estudiado en los casos de Sevilla y Granada ${ }^{51}$. En Córdoba también se pueden rastrear testimonios en la misma línea desde la implantación del tribunal, que muestran la vida de las perpetuas como una suerte de prisión abierta en la que pesaba mucho más la necesidad de ganarse el sustento que el encerramiento en sí, que era casi inexistente ${ }^{52}$.

Éste es el caso de Martín Alonso de Membreque, procesado por segunda vez por los años 1506-1511. El tribunal de Córdoba ya lo había sentenciado a llevar sambenito y a guardar cárcel perpetua, pero él decidió escapar cuando vio la persecución que Lucero comenzó a hacer a su familia, acusada de judaizar. Abandonó la ciudad, e incluso el reino, tomando una nao en Portugal. Sin embargo, fue pillado y regresó a Córdoba, donde se le abrió proceso una vez

49 Punto 22 de la relación enviada por el visitador Luis de Copones a la Suprema, con motivo de la inspección al tribunal cordobés en los años 1588-89. AHN, Inquisición, Leg. 4724² ff. 6r-6v. (Gracia BoIX, Rafael: Colección de documentos para la bistoria de la Inquisición de Córdoba, Córdoba, 1982 , pp. 227-228).

so El estado de desarreglo que se mostró para el caso de las cárceles secretas parecía repetirse para el de las perpetuas, dibujando un panorama de precariedad arquitectónica del que ya se tenían noticias en 1578, y que estaba básicamente condicionado por el concepto de edificio penitenciario que se tenía en el Antiguo Régimen.

sı Los presos entraban y salían de la cárcel perpetua granadina durante el día, siempre que llevaran puestos sus sambenitos, y regresaban a la hora de dormir. En el vecino tribunal de Sevilla, ni siquiera eso, ya que debido al particular aislamiento del castillo de Triana, sede de la Inquisición, si los presos habían ido a trabajar a Sevilla «no podrían volver a tiempo a recogerse las noches por la distancia y descomodidades del puente.» (DOMínguez OrTIZ, Antonio: Los autos de la Inquisición de Sevilla (siglo XVII), Sevilla, 1981, p. 51). Para el caso granadino, véase SÁNCHEZ ORTEGA, $\mathbf{M}^{\mathrm{a}}$ Helena, «La situación...», op. cit.

52 En palabras de Bernard VINCENT, «La prison «perpétuelle», lieu de séjour des condamnés, est matériellement mal define et fluctuante, quand ce $n$ ' est pas inexistante.» (VINCENT, Bernard: «Un espace...», op. cit., pp. 114-115).

Hispania, LXV/2, núm. 220 (2005) 443-464 
más y se le acabó enviando de nuevo a la cárcel perpetua (salvándose casi milagrosamente de la hoguera). El mismo Martín Alonso de Membreque mostró las precariedades que padecía después de haber sido procesado por el Santo Oficio, haciendo un balance de su vida en el que se encuentra, de nuevo, la libertad de la cárcel perpetua. Éstas son sus palabras (la cursiva es mía):

«[...] despues que yo me reconçilie de mis pecados, non he fecho cosa alguna, saluo he vivido como viuen cristiano e he fecho non lejos de buen çristiano en lo qual pido miçericordia a sus Reberençias de la quitada del abito porque entonşes non estava en la carcel perpetua saluo por la çibdad que andava muy perdido e roto, e desnudo yo e mis fijos e muger e con la provesa e dubda, llebe alla el dicho abito que me quete por provesa e negegidad e dubdas, que non me pordia valerss3.

Otro testimonio describe una situación similar medio siglo más tarde, en 1555. Este año los inquisidores de Córdoba enviaron a la Suprema una causa sustanciada en el tribunal para efectuar una consulta. En ella muestran el comportamiento de Maestre Ham en las cárceles perpetuas (la cursiva es mía):

«Este reo, es gran borracho y perdido, y algunas vezes hablaua como ayrado, satisfiço mal a su testificaçion, y acuerdome que temiendo no diese con sus confesiones en tierra, no lo osamos poner en tormento. Yo hasta oy sospechoso estoy del. No está en la carçel perpetua ni lo bastan a tener en ella, salese a emborrachar con quantos flamencos y alemanes puede hallar, y caballeros lo traen por sus casas a hazer cosas, porque es muy primo platero, y con todo esto, no tiene un pan ni avn para vnos çapatos, en su manera y trato, paresçe, a los que lo conversan, mas vestia que hombre, y en su arte, el rato que está sin vino, dizen que es de maravillar lo que haze, no consta de impenitencia» 54 .

Cuando el reo conseguía organizar su vida en ella, la cárcel perpetua resultaba un alojamiento interesante. Esto hizo que en algunas Inquisiciones se dieran casos de presos que, una vez cumplida su sentencia, no quisieran abandonar la celda, tras haberse adecuado a ese régimen de vida, con su espacio acondicionado y sin tener que pagar el coste elevado de un alquilerss.

\section{La cárcel de familiares}

En una sociedad de desigualdades como era la sociedad del Antiguo Régimen, no podía incluirse a todos los reos en las cárceles secretas, como si todos fueran de la misma cuna. Si se apresaba a alguno de las propias filas inquisito-

s3 AHN, Inquisición, Leg. 4724, doc. 3, f. 6v. (Gracia BoIX, Rafael: Colección..., op. cit., p. 114).

54 AHN, Inquisición, Leg. 4442, doc. 10, f. 2r. (Ibídem, p. 147).

ss Algunos ejemplos sevillanos son recogidos por Antonio Domínguez OrTIZ, Autos..., op. cit., p. 51 y «Aspectos...», op. cit., p. 295. 
riales, se le llevaba a la denominada cárcel de familiares, en la que se beneficiaba de un régimen de libertad mayor que el absolutamente hermético que se pretendía para las secretas.

Hacia 1588 la cárcel de familiares se encontraba en una situación aún peor que la perpetua, ya que por esas mismas fechas no existía siquiera, después de que el espacio en que se encontraba fuera reconvertido en audiencia del juzgado y «escriptorio del Notario de Secrestos» ${ }^{56}$. De esta forma, cuando se apresaba a algún miembro del Santo Oficio, el tribunal no tenía más remedio que recurrir a meterlo en la cárcel de la ciudad, lo que era un inconveniente si el caso salpicaba algún tema de jurisdicción.

En sendas cartas de 9 de diciembre de 1585 y 6 de noviembre de 1587, los inquisidores de Córdoba dieron cuenta del estado de este asunto al Inquisidor General, proponiendo, además, que se reubicara la cárcel de familiares en una vieja atarazana deshabilitada del Alcázar. Pese a que éste les respondió solicitando un desglose de lo que podría costar su adaptación, el tribunal dejó la cuestión suspensa hasta la fecha de la visita de inspección (1588-89), cuando determinaron que el maestro de obras hiciese relación de las $\operatorname{costas}^{57}$. La cárcel aún tardaría en realizarse. A la altura de 1592, el tribunal volvía a dirigirse al Consejo solicitando que se construyera ${ }^{58}$, algo que finalmente se realizaría - aunque desconocemos exactamente la demora - , pues casi medio siglo más tarde su existencia salía a relucir en diversas testificaciones de la inspección de $1645^{59}$.

En ella no sólo se recluía a los miembros del Santo Oficio, sino también a aquellos reos que por blasfemar continuadamente y alborotar, hacían escándalo y debían ser separados del resto; incluidos aquéllos de los que se temía algún intento de fuga ${ }^{60}$. Sin embargo, se daba la contradicción de que la cárcel de familiares resultaba menos segura que la secreta. Por esto, cuando en 1644 se procesó a Francisco de Pernia, se le colocó en la de entrepuertas «que es carçel differente y de gran custodia, y debajo de la misma llave, con que se guardan

56 Punto 23 de la relación enviada por el visitador Luis de Copones a la Suprema, con motivo de la inspección al tribunal cordobés en los años 1588-89. AHN, Inquisición, Leg. $4724^{2}$, f. 6v. (Gracia BoIX, Rafael, Colección..., op. cit., p. 228).

57 Ibidem.

58 AHN, Inquisición, Leg. 2395, s.f. En Córdoba, a 12 de noviembre de 1592.

59 Véanse: testificación de don Fernando Calbo de Monjurio, casado con una sobrina del Inquisidor Don Antonio Hurtado (en Córdoba, 19 de febrero de 1647. AHN, Inquisición, Leg. 1855, exp. 4, f. 30v), testificación de Gaspar de Águila (AHN, Inquisición, Leg. 1855, exp. 1, ff. 209r209v. Córdoba, 20 de octubre de 1644), testimonio del alcaide de las cárceles Francisco Rodríguez Moreno (AHN, Inquisición, Leg. 1855, exp. 4, ff. 53-54v. Córdoba, 23 de noviembre de 1646), cargo 27 de los añadidos contra el inquisidor don Antonio Hurtado (Ibídem, s.f. Dado en Córdoba, a 21 de enero de 1647), y el proceso del ayudante del alcaide de las cárceles, Francisco de Pernia (Ibidem, ff. 1r-1v).

60 BN, Mss. 2440, f. 43.

Hispania, LXV/2, núm. 220 (2005) 443-464 
las carçeles secretas» ${ }^{61}$, a pesar de que en todos los autos y documentación enviada al Consejo habían puesto que lo habían recluido en la de familiares, como ayudante del alcaide que era. Curiosamente, habida cuenta de que el reo sabía muchísimo sobre los otros procesados cuyas causas estaban en curso, la Suprema pensó lo mismo que los inquisidores, y remitió carta para que no dejaran a Francisco de Pernia en la cárcel de familiares, "que es carçel abierta» ${ }^{62}$, sino que lo trasladaran a las cárceles secretas, mucho más seguras; algo que éstos ya habían hecho y de lo que se vieron obligados a informar.

\section{Mujeres entre rejas}

Las instrucciones dispusieron que en las celdas hubiera separación de sexos y así se encuentran en el caso cordobés durante las visitas de cárceles de 1569. Las recién llegadas solían llevarse a la Cámara o a la cárcel del Portillo, para pasar posteriormente a la del Horno, con el resto de reclusas, en caso de que la estancia se fuera a dilatar más ${ }^{63}$.

Los interrogatorios-tipo usados por los visitadores en las inspecciones internas de los tribunales incluían una cuestión por la que se debía comprobar, no sólo que las presas se encontraran en celdas diferentes a las de los hombres, sino también si los miembros del tribunal habían abusado sexualmente de ellas mientras duró su reclusión ${ }^{64}$, algo relativamente fácil de hacer gracias al secreto inquisitorial, de lo que se quejaban en Granada el año de $1526^{65}$. Y es que la estimación de la mujer pobre en la Edad Moderna dentro del grupo de marginados sociales, unida a la escasa profesionalidad de ciertos cuadros, la facilidad de quedar impunes tras su

61 Memorial de don Juan de Rivera con sus réplicas a los cargos que se le habían imputado en la visita de inspección de 1645. Córdoba, 22 de enero de 1646. AHN, Inquisición, Leg. 1855, exp. 2, ff. 6r-10r. La cita en f. 6r.

62 Ibídem.

63 En las cárceles de la Inquisición de Lisboa la división era absoluta: en el cuarto bajo estaban los hombres, y en uno alto se recluía a las mujeres. BN, Mss. 718, f. 315.

64 Como ejemplo, la pregunta 38 del interrogatorio de la visita de inspección que Gómez de Carvajal efectuó en 1577: «Yten si sauen que las mugeres que estan presas estan apartadas y en carçel diferente que la de los hombres y si sauen que en la carçel o fuera sea fecho alguna deshonestidad con ellas estando presas.» AHN, Inquisición, Leg. 1853, exp. 2, s.f. El miedo que causaba el Santo Oficio entre el pueblo se aliaba en ocasiones con los ministros de la Inquisición para satisfacer sus apetitos sexuales incluso con las familiares de los presos: " 5 . Yten si sauen que los inquisidores biuian honestamente sin tener mancebas publicas y sin tener açesso con las presas y con mugeres ó hijas ó parientes de presos ó difuntos llamados por el santo offiçio de sus parientes de los tales llamados ó si alguno de los offiçiales ayan currido en lo susodicho». Ibídem.

65 GUTIÉRREZ NiETO, Juan Ignacio: «Inquisición y culturas marginadas: conversos, moriscos y gitanos», AA.VV., El siglo del Quijote (1580-1680). Vol I: Religión, filosofía, ciencia, Madrid, 1996, pp. 837-1016; la cita en p. 858.

Hispania, LXV/2, núm. 220 (2005) 443-464 
abuso de autoridad y el concepto que se tenía del castigo corporal en la configuración de las actitudes sociales, se conjugaban en detrimento de la prisionera.

Pese a ello, la mayor parte de los suicidios de presos son masculinos, a pesar de que las reas tuvieron que soportar, en ocasiones, abusos mayores que los padecidos por sus compañeros varones ${ }^{66}$. Un balance desproporcionado en cuanto a los suicidios es frecuente. Los estudios sobre la historia de éste y sus análisis sociológicos muestran como habitual una mayoría de muertes masculinas, pues son los hombres quienes consiguen una mayor efectividad en sus intentonas suicidas. Un ejemplo significativo es el caso de Isabel de San Juan, que, apresada en 1635 junto a sus cinco hermanas y acusada de judaizar, se vio tan desesperada en la celda, tras casi dos años de proceso, que pidió audiencia para

«[...] manifestar la verdad, que estaba todavía en la ley de Moisés, que como la mamó en la leche, cuando le daban inspiraciones de volverse a la fe de Nuestro Señor Jesucristo, pensaba que se había de perder su ánima y estaba en gran confusión; y que había llegado a tanto el trabajo que había tenido, que una noche se había querido matar $[\ldots]{ }^{67}$

Sus intentonas suicidas se quedarían en eso. Aunque también hay casos de reas en el tribunal de Córdoba que llevaron a último extremo su propósito, como doña Ana Perea y Faro ${ }^{68}$ o la joven Anna Rodriguez ${ }^{69}$.

En otro orden de cosas, los rumores populares contribuían a extender el convencimiento de las violaciones de presas dentro de las celdas - algo que en ocasiones fue motivo de indagación por parte del tribunal ${ }^{70}$. Aunque, teniendo en cuenta que los procesos por lo general se dilataban muchísimo y que en teoría no había contactos entre las reas y hombres del exterior, quizás no sea exagerado el escándalo que causó en Córdoba el que saliera a un auto de fe una presa que había parido en las cárceles secretas, con su bebé en brazos. El hecho dio ocasión a que se sospechara que en las celdas no se guardaba la honestidad debida. Por este motivo, el doctor Luis de Copones, tras su inspección al tribunal en los años 1588-89, propone una particular solución coyuntural en tales situaciones:

«Conuiene mandar que de aquí adelante, no se saque al Auctho con criatura, ninguna muger que ouiere parido en las Carceles, y que los Ynquisidores prouean

${ }_{66}$ También Victoria González de Caldas ha estudiado cómo las mujeres solían soportar mejor, por lo general, las condiciones adversas. (GONZÁlEZ DE CALDAS, Victoria: ¿Judios o cristianos? El Proceso de Fe Sancta Inquisitio, Sevilla, 2000, p. 278).

67 Gracia BoIX, Rafael: Autos de fe..., op. cit., p. 135.

68 AHN, Inquisición, Leg. 2420, s.f.

69 AHN, Inquisición, Leg. 4972, caja 1, exp. 14, s.f.

70 El 4 de marzo de 1577 el fiscal presenta una petición relativa al proceso de algunas de las brujas de Montilla. En el punto tercero recuerda que, respecto a María de la Encarnación, presa, falta por averiguar «su preñado en la cárcel». AHN, Inquisición, Leg. $2393^{2}$, s.f. (HUERGA, Álvaro: Historia de los alumbrados de la Alta Andalucía (1575-1590), Madrid, 1978, p. 94). 
como quede a recaudo la criatura entre tanto que la tal muger estuuiere en el Auctho» 71 .

\section{CONCLUSIONES}

A la hora de estudiar las cárceles de la Edad Moderna, mucho más en el caso de las celdas del Santo Oficio, hay que tener presente no sólo la diversidad carcelaria, sino el procedimiento inquisitorial, enmarcado en un contexto punitivo heredado de la Edad Media. De esta forma, los calabozos que tratamos están imbuidos del concepto de cárcel-custodia, a lo que suman el carácter preventivo de la prisión inquisitorial y el secreto que debía regir todas las actuaciones del Santo Oficio. A la luz de estas premisas, casi carecen de sentido las frecuentes comparaciones que se han querido establecer entre las condiciones de vida de cárceles laicas e inquisitoriales para demostrar la benignidad de unas y los abusos de otras, pues cada una suponía, como se ha visto, una pesadilla para sus prisioneros.

En función del estadio del proceso, la Inquisición disponía de dos tipos de cárceles: las secretas, donde los reos esperaban el desarrollo y la resolución de su negocio, y las perpetuas, donde cumplían pena de carcelería. Por otro lado se encontraba la cárcel de familiares, para miembros del tribunal o presos especiales, y las celdas de mujeres. En todas ellas, la posición socioeconómica hacía más llevadero el encerramiento, al poder disponer de ciertos elementos de prestigio y, sobre todo, de la tan deseada compañía que tantos presos solicitaron infructuosamente en las visitas de cárceles -y que algunos obtuvieron por evitar que cayeran en la locura.

La teoría habría hecho de todas las celdas unos espacios más cómodos, seguros y limpios de lo que eran. Sin embargo, la realidad se muestra en toda su crudeza en los escasos testimonios que reflejan la vida en los calabozos cordobeses y es así como se comprueba que las secretas eran focos de enfermedades y muerte, que los inquisidores no llegaban a controlar la libertad vigilada de los presos de las perpetuas, que en la cárcel de familiares a veces no se debía encerrar al personal del Santo Oficio, que algunos miembros del tribunal mantenían frecuentes relaciones sexuales con las reas, y que, en definitiva, amén de las reformas incoherentes, el dinero destinado al mantenimiento de los prisioneros y de sus calabozos no siempre se gastó adecuadamente y en quienes se suponía.

Pese a ello, la correspondencia entre la Inquisición y la Suprema refleja la preocupación por que los presos se encontraran bien acomodados, y no en celdas que se caían a pedazos y que ponían en peligro tanto el secreto del tribunal

71 Punto 22 de la relación que el visitador Luis de Copones envió a la Suprema tras su inspección al tribunal de Córdoba, los años 1588-89. AHN, Inquisición, Leg. 4724², ff. 5r-5v. (GraCiA BoIx, Rafael: Colección..., op. cit., p. 203). 
como la salud de sus ocupantes. Ejemplo de ello es la respuesta que el Consejo envía a Córdoba el 12 de febrero de 1574, por la que ordenaba que se tomaran medidas efectivas para que esto tuviera lugar. Desde el tribunal se respondió el 24 de abril, avanzando un modelo de reforma:

«[...] pareçe que lo mas util y seguro seria que en el compas del adarbe hasta las audiencias y aposento del alcaide se hiziesen carçeles soterranas, y con bobedas encima, y sobre la bobeda otras carceles que no se podrian comunicar, con ser muy gruesa, y maçiçada la bobeda» 72 .

Pero a pesar de idear una buena solución arquitectónica, el elevado coste de la obra, de aproximadamente tres mil reales, les hizo no enviar a la Suprema traza alguna y sí sugerir que, en opinión de los oficiales, se podrían reparar y fortificar las cárceles existentes, con un coste de unos mil ducados.

En este caso, como en tantos otros a lo largo de la historia del tribunal, estaba claro que el estado en que se encontraban los prisioneros no era el adecuado; sin embargo, el dinero, las molestias, la desidia, se conjugaban en contra de los presos y también en contra de ellos mismos, del procedimiento inquisitorial, enquistando el problema del espacio carcelario en la Inquisición de Córdoba. En cualquier caso, en la diferencia entre cuadros y presos no había sitio para las responsabilidades. Y, así, los miembros del Santo Oficio no contaron con la indefensión de los prisioneros cuando las supuestas maldiciones comenzaron a asolar la sede y a mermar a sus habitantes con enfermedades continuas. De esta forma, aunque fueron los primeros en abandonar las estancias seguían abogando por el arreglo de aquellas celdas estrechas, húmedas e insalubres donde se consumían los prisioneros. Contradicciones humanas.

72 AHN, Inquisición, Leg. $2393^{1}$, s.f.

Hispania, LXV/2, núm. 220 (2005) 443-464 